\title{
Are Dividend Yield and ROE Smart Portfolio Fundamentals? The Recent Case of Japan
}

\author{
Chikashi Tsuji \\ Professor, Faculty of Economics, Chuo University \\ 742-1 Higashinakano, Hachioji-shi, Tokyo 192-0393, Japan \\ E-mail:mail_sec_low@minos.ocn.ne.jp
}

Received: March 11, 2016

Accepted: April 1, 2016 Published: April 7, 2016

doi:10.5296/bmh.v4i1.9272

URL: http://dx.doi.org/10.5296/bmh.v4i1.9272

\begin{abstract}
This paper attempts to test whether dividend yield and ROE are important fundamentals for obtaining positive alpha by using a four factor asset pricing model. As a result, our investigations derive several interesting findings as follows. First, (1) we clarify that for the period from January 2009 to March 2013, our second highest and third highest dividend-yield portfolios deliver statistically significant positive alphas. Second, (2) we also reveal that for the period from January 2009 to March 2013, our second highest and third highest ROE portfolios yield statistically significant positive alphas. Overall, our empirical examinations demonstrate that after the Lehman shock period, dividend yield and ROE are the important fundamentals for constructing smart portfolios in Japan.
\end{abstract}

Keywords: Asset pricing model, Dividend yield, ROE, Smart beta 


\section{Introduction}

After serious financial crises, many investors become increasingly interested in alternative investment strategies, called as smart beta, instead of conventional market capitalization-based indices. Currently, smart beta seems not to have a strict definition, and it can be understood as rule-based investment strategies, in which the traditional market capitalization weights are not employed. It can be considered that such traditional schemes yield only sub-optimal returns since they may overweight overvalued equities and underweight undervalued equities. It is also recognized that smart beta strategies are those aim at attaining a better risk-return profile than those from conventional indexing schemes by constructing indices or portfolios based on such measures as cash flows, liquidity, volatility, and/or earnings. Most importantly, are then these strategies effective in the real world equity portfolio management?

In order to answer the above question, as a case study, this paper attempts to test whether dividend yield and ROE are important fundamentals for obtaining positive risk-adjusted return. As a result, our investigations find interesting evidence as follows. First, (1) we find that for the period from January 2009 to March 2013, our second highest and third highest dividend-yield portfolios deliver statistically significant positive alphas. Second, (2) we also clarify that for the period from January 2009 to March 2013, our second highest and third highest ROE portfolios also produce statistically significant positive alphas. As above, our empirical examinations in this paper demonstrate that after the Lehman shock period, dividend yield and ROE are useful fundamentals for constructing smart portfolios in Japan. After this introduction, Section 2 conducts literature review; Section 3 documents our data; and Sections 4 explains our model. Section 5 reports our results and finally, Section 6 concludes the paper.

\section{Literature Review}

This section concisely reviews related studies; however, we note that there is little previous study regarding smart beta. First, a practical research by Shepherd (2014) implemented some analyses related to the smart beta investing in corporate bonds. A recent paper by Malkiel (2014) suggested that smart beta strategies were not effective. Further, Hsu et al. (2015) implemented robustness checks for value, momentum, beta, quality, illiquidity, and size factors by using the Sharpe ratio in several international stock markets in the context of smart beta strategies. They reported mixed results for the effectiveness of the strategies they tested. AlMahdi (2015) tested several smart beta strategies and the paper reported that one portfolio was stable under stress and another portfolio could be used to obtain higher returns.

Moreover, using European stock data for the period from March 15, 2002 to May 1, 2012, Bertrand \& Lapointe (2015) investigated the effects of the use of a socially responsible investment (SRI) universe on the performance of risk-based asset allocation strategies. They found that the use of the SRI universe had a positive contribution to risk-adjusted performance of risk-based asset allocations; however, they also suggested that this contribution was not uniform and represented only a small part of the total alpha that was observed in their study. 
Table 1. Descriptive statistics of the Japanese equity portfolios sorted by dividend yields and ROE: for the period from July 1987 to March 2013

\begin{tabular}{|c|c|c|c|c|c|}
\hline \multicolumn{6}{|c|}{ Panel A. Dividend yield portfolios } \\
\hline & $\mathrm{P} 1$ & $\mathrm{P} 2$ & P3 & $\mathrm{P} 4$ & $\mathrm{P} 5$ \\
\hline Mean & 0.9480 & 0.5885 & 0.4936 & 0.3880 & 0.2282 \\
\hline Median & -0.0300 & 0.6000 & 0.5200 & 0.3000 & 0.0900 \\
\hline Maximum & 196.3000 & 31.9000 & 22.1400 & 20.9100 & 20.9800 \\
\hline Minimum & -22.4600 & -18.7600 & -17.9200 & -18.8500 & -17.9500 \\
\hline Standard deviation & 12.7000 & 6.1259 & 5.9529 & 5.9988 & 5.7115 \\
\hline Skewness & 11.8312 & 0.4374 & 0.0356 & 0.1372 & -0.0254 \\
\hline \multirow[t]{2}{*}{ Kurtosis } & 182.5947 & 5.5401 & 4.1690 & 3.9773 & 3.8221 \\
\hline & P6 & P7 & P8 & P9 & $\mathrm{P} 10$ \\
\hline Mean & 0.3203 & 0.3191 & 0.0493 & -0.1072 & -0.3132 \\
\hline Median & 0.4400 & 0.2100 & 0.1500 & 0.1600 & -0.6200 \\
\hline Maximum & 26.2600 & 19.3500 & 21.0000 & 19.1300 & 21.7200 \\
\hline Minimum & -19.6800 & -18.6900 & -22.6200 & -22.8600 & -22.6500 \\
\hline Standard deviation & 5.8997 & 5.5725 & 5.8841 & 6.2104 & 7.1712 \\
\hline Skewness & 0.0828 & -0.1709 & -0.0557 & -0.3146 & 0.0043 \\
\hline Kurtosis & 4.5578 & 3.9259 & 4.0986 & 3.8918 & 3.4408 \\
\hline \multicolumn{6}{|c|}{ Panel B. ROE portfolios } \\
\hline & $\mathrm{P} 1$ & $\mathrm{P} 2$ & P3 & $\mathrm{P} 4$ & P5 \\
\hline Mean & 0.0386 & 0.0974 & 0.2108 & 0.1394 & 0.3284 \\
\hline Median & 0.0000 & 0.0900 & 0.2300 & 0.1100 & 0.5000 \\
\hline Maximum & 20.5500 & 21.2600 & 17.8600 & 18.1100 & 18.2700 \\
\hline Minimum & -24.5600 & -21.8000 & -19.2500 & -20.6600 & -20.4400 \\
\hline Standard deviation & 6.8093 & 5.9797 & 5.5229 & 5.3276 & 5.3475 \\
\hline Skewness & -0.1176 & -0.1046 & -0.0636 & -0.1090 & -0.2339 \\
\hline \multirow[t]{2}{*}{ Kurtosis } & 3.8580 & 4.0899 & 3.8467 & 3.8197 & 4.1130 \\
\hline & P6 & P7 & P8 & P9 & $\mathrm{P} 10$ \\
\hline Mean & 0.1426 & 0.2338 & 0.0074 & 0.2988 & 0.0668 \\
\hline Median & 0.4000 & 0.0500 & 0.2100 & 0.0500 & -0.2700 \\
\hline Maximum & 18.4100 & 24.9900 & 22.3400 & 74.7300 & 26.7600 \\
\hline Minimum & -18.0200 & -18.0000 & -19.9000 & -23.8600 & -20.7200 \\
\hline Standard deviation & 5.5330 & 5.8824 & 6.1804 & 7.9117 & 7.6697 \\
\hline Skewness & -0.0381 & 0.2455 & 0.0703 & 2.6802 & 0.1973 \\
\hline Kurtosis & 3.9237 & 4.3965 & 3.7486 & 27.5881 & 3.6193 \\
\hline
\end{tabular}

Notes. In this table, 'P' means portfolio and in Panel A, P1 shows the highest dividend-yield equity portfolio and P10 means the lowest dividend-yield portfolio. In Panel B, P1 denotes the highest return on equity (ROE) stock portfolio and P10 means the lowest ROE portfolio. The number of the monthly observations in our full sample period is 309 . 


\section{Data}

In this section, we document the data used in this research. This study uses four factors for the asset pricing model; ten returns of the portfolios ranked by dividend yields; and ten returns of the portfolios ranked by ROE for Japanese stock markets. All data except for the Tokyo stock price index (TOPIX), which are used in this study are kindly supplied by Stefano Marmi. TOPIX data are from the Quick Corp.

Table 1 displays the descriptive statistics of the Japanese equity portfolios sorted by dividend yields and ROE for the period from July 1987 to March 2013. In this table, in Panel A, P1 shows the highest dividend-yield equity portfolio and P10 means the lowest dividend-yield portfolio. In addition, in Panel B, P1 denotes the highest ROE stock portfolio and P10 means the lowest ROE portfolio. As far as this full sample period, we understand first that (1) higher dividend-yield portfolios show the higher returns; while somewhat differently, it is also understood that (2) higher ROE portfolios do not necessarily yield higher returns in general.

\section{The Model}

This section documents our empirical asset pricing model, which is to evaluate the performance of our dividend-yield and ROE based portfolios. More specifically, the model used in our tests is the following four factor asset pricing model (1):

$$
R_{p, t}=\alpha_{p}+\tau_{p}\left(R_{M}-R_{F}\right)+\chi_{p} S M B_{t}+\phi_{p} H M L_{t}+\xi_{p} W M L_{t}+\kappa_{p, t} \cdot
$$

In the above model, $\mathrm{R}_{\mathrm{p}, \mathrm{t}}$ denotes one of the returns of the portfolios ranked by dividend yields or ROE; $\mathrm{R}_{\mathrm{M}}-\mathrm{R}_{\mathrm{F}}$ denotes the excess market return over the risk free rate; SMB means the small stock premium factor; HML denotes the value premium factor; and WML means the momentum factor. Namely, this four factor model comprises Fama-French (1993) three factor model and a momentum factor. Using this model, we examine the existence of the positive risk-adjusted returns: positive alphas in the portfolios ranked by dividend yields or ROE. 
Table 2. Estimation results of the four factor asset pricing model for the dividend-yield equity portfolios in Japan

Panel A. Results from July 1987 to December 2008

\begin{tabular}{|c|c|c|c|c|c|}
\hline \multicolumn{3}{|l|}{$\mathrm{P} 1$} & \multicolumn{3}{|l|}{$\mathrm{P} 2$} \\
\hline & Coefficient & $p$-value & & Coefficient & $p$-value \\
\hline Alpha & $-0.8369 * * *$ & 0.0001 & Alpha & 0.2338 & 0.1939 \\
\hline EMR & $0.9767 * * *$ & 0.0000 & EMR & $0.8556^{* * *}$ & 0.0000 \\
\hline SMB & $-0.3460 * * *$ & 0.0000 & SMB & $0.3158 * * *$ & 0.0000 \\
\hline HML & $1.3433^{* * *}$ & 0.0000 & HML & $0.2934 * * *$ & 0.0000 \\
\hline WML & $-0.2988 * * *$ & 0.0000 & WML & $-0.3079 * * *$ & 0.0007 \\
\hline Adj. $R^{2}$ & \multicolumn{2}{|c|}{0.9175} & Adj. $R^{2}$ & \multicolumn{2}{|c|}{0.7952} \\
\hline \multicolumn{3}{|l|}{$\mathrm{P} 3$} & \multicolumn{3}{|l|}{$\mathrm{P} 4$} \\
\hline & Coefficient & $p$-value & & Coefficient & $p$-value \\
\hline Alpha & 0.1980 & 0.2566 & Alpha & 0.1194 & 0.4762 \\
\hline EMR & $0.8771 * * *$ & 0.0000 & EMR & $0.9001 * * *$ & 0.0000 \\
\hline SMB & $0.2516 * * *$ & 0.0000 & SMB & $0.1757 * * *$ & 0.0003 \\
\hline HML & $0.2098 * * *$ & 0.0000 & HML & $0.2411 * * *$ & 0.0000 \\
\hline WML & $-0.2624 * * *$ & 0.0007 & WML & $-0.2393 * * *$ & 0.0006 \\
\hline Adj. $R^{2}$ & \multicolumn{2}{|c|}{0.8160} & Adj. $R^{2}$ & \multicolumn{2}{|c|}{0.8336} \\
\hline \multicolumn{3}{|l|}{ P5 } & \multicolumn{3}{|l|}{ P6 } \\
\hline & Coefficient & $p$-value & & Coefficient & $p$-value \\
\hline Alpha & 0.0898 & 0.5640 & Alpha & 0.1400 & 0.3088 \\
\hline EMR & $0.8905 * * *$ & 0.0000 & EMR & $0.9426 * * *$ & 0.0000 \\
\hline SMB & $0.0843^{* *}$ & 0.0368 & SMB & 0.0725 & 0.1031 \\
\hline HML & $0.0682 * *$ & 0.0452 & HML & $0.1055 * * *$ & 0.0036 \\
\hline WML & $-0.1847 * * *$ & 0.0053 & WML & $-0.1341 * *$ & 0.0118 \\
\hline Adj. $R^{2}$ & \multicolumn{2}{|c|}{0.8404} & Adj. $R^{2}$ & \multicolumn{2}{|c|}{0.8479} \\
\hline \multicolumn{3}{|l|}{ P7 } & \multicolumn{3}{|l|}{ P8 } \\
\hline & Coefficient & $p$-value & & Coefficient & $p$-value \\
\hline Alpha & 0.2126 & 0.1050 & Alpha & 0.0955 & 0.5187 \\
\hline EMR & $0.8866 * * *$ & 0.0000 & EMR & $0.9038 * * *$ & 0.0000 \\
\hline SMB & 0.0552 & 0.1560 & SMB & $-0.1671 * * *$ & 0.0011 \\
\hline HML & 0.0258 & 0.3851 & HML & $-0.1154 * * *$ & 0.0017 \\
\hline WML & $-0.1185^{* * *}$ & 0.0008 & WML & $-0.1082 *$ & 0.0722 \\
\hline Adj. $R^{2}$ & \multicolumn{2}{|c|}{0.8684} & Adj. $R^{2}$ & \multicolumn{2}{|c|}{0.8443} \\
\hline \multicolumn{3}{|l|}{ P9 } & \multicolumn{3}{|l|}{$\mathrm{P} 10$} \\
\hline & Coefficient & $p$-value & & Coefficient & $p$-value \\
\hline Alpha & -0.0704 & 0.6327 & Alpha & -0.1748 & 0.5305 \\
\hline EMR & $0.9864 * * *$ & 0.0000 & EMR & $1.1028 * * *$ & 0.0000 \\
\hline SMB & $-0.1589 * * *$ & 0.0002 & SMB & $-0.1538^{*}$ & 0.0634 \\
\hline HML & $-0.1104 * * *$ & 0.0014 & HML & $-0.2100 * * *$ & 0.0063 \\
\hline WML & -0.0351 & 0.3783 & WML & 0.0358 & 0.7236 \\
\hline Adj. $R^{2}$ & \multicolumn{2}{|c|}{0.8599} & Adj. $R^{2}$ & \multicolumn{2}{|c|}{0.7647} \\
\hline
\end{tabular}




\begin{tabular}{|c|c|c|c|c|c|}
\hline \multicolumn{3}{|l|}{$\mathrm{P} 1$} & \multicolumn{3}{|l|}{$\mathrm{P} 2$} \\
\hline & Coefficient & $p$-value & & Coefficient & $p$-value \\
\hline Alpha & -0.1541 & 0.6279 & Alpha & $0.4552 * *$ & 0.0421 \\
\hline EMR & $1.0106^{* * *}$ & 0.0000 & EMR & $0.9076^{* * *}$ & 0.0000 \\
\hline SMB & $0.2563^{*}$ & 0.0611 & SMB & $-0.2538 * * *$ & 0.0047 \\
\hline HML & $0.3102 * *$ & 0.0326 & HML & 0.0478 & 0.5831 \\
\hline WML & $-0.3415^{* * *}$ & 0.0040 & WML & 0.0706 & 0.2047 \\
\hline Adj. $R^{2}$ & \multicolumn{2}{|c|}{0.8281} & Adj. $R^{2}$ & \multicolumn{2}{|c|}{0.9170} \\
\hline \multicolumn{3}{|l|}{ P3 } & \multicolumn{3}{|l|}{ P4 } \\
\hline & Coefficient & $p$-value & & Coefficient & $p$-value \\
\hline Alpha & $0.4822 * *$ & 0.0287 & Alpha & -0.0117 & 0.9723 \\
\hline EMR & $0.8853^{* * *}$ & 0.0000 & EMR & $0.9169^{* * *}$ & 0.0000 \\
\hline SMB & -0.0848 & 0.4753 & SMB & -0.0221 & 0.8638 \\
\hline HML & $0.3895^{* * *}$ & 0.0018 & HML & 0.0137 & 0.9483 \\
\hline WML & 0.0246 & 0.7421 & WML & -0.0394 & 0.6139 \\
\hline Adj. $R^{2}$ & \multicolumn{2}{|c|}{0.8948} & Adj. $R^{2}$ & \multicolumn{2}{|c|}{0.8136} \\
\hline \multicolumn{3}{|l|}{$\mathrm{P} 5$} & \multicolumn{3}{|l|}{ P6 } \\
\hline & Coefficient & $p$-value & & Coefficient & $p$-value \\
\hline Alpha & 0.2882 & 0.1007 & Alpha & 0.3493 & 0.3395 \\
\hline EMR & $0.8585^{* * *}$ & 0.0000 & EMR & $0.9209 * * *$ & 0.0000 \\
\hline SMB & 0.0471 & 0.4268 & SMB & 0.1226 & 0.3300 \\
\hline HML & 0.0874 & 0.2715 & HML & 0.1625 & 0.1554 \\
\hline WML & $-0.1572 * * *$ & 0.0000 & WML & 0.0138 & 0.7579 \\
\hline Adj. $R^{2}$ & \multicolumn{2}{|c|}{0.9211} & Adj. $R^{2}$ & \multicolumn{2}{|c|}{0.8784} \\
\hline \multicolumn{3}{|l|}{$\mathrm{P} 7$} & \multicolumn{3}{|l|}{ P8 } \\
\hline & Coefficient & $p$-value & & Coefficient & $p$-value \\
\hline Alpha & 0.3047 & 0.1995 & Alpha & 0.0341 & 0.8996 \\
\hline EMR & $0.8897 * * *$ & 0.0000 & EMR & $0.9928 * * *$ & 0.0000 \\
\hline SMB & 0.1064 & 0.2396 & SMB & -0.0577 & 0.5728 \\
\hline HML & -0.0022 & 0.9683 & HML & 0.0604 & 0.5990 \\
\hline WML & $-0.1655^{* * *}$ & 0.0021 & WML & -0.0851 & 0.2505 \\
\hline Adj. $R^{2}$ & \multicolumn{2}{|c|}{0.8788} & Adj. $R^{2}$ & \multicolumn{2}{|c|}{0.8671} \\
\hline \multicolumn{3}{|l|}{ P9 } & \multicolumn{3}{|l|}{$\mathrm{P} 10$} \\
\hline & Coefficient & $p$-value & & Coefficient & $p$-value \\
\hline Alpha & -0.2085 & 0.3809 & Alpha & 0.0683 & 0.7671 \\
\hline EMR & $1.0047^{* * *}$ & 0.0000 & EMR & $0.9504^{* * *}$ & 0.0000 \\
\hline SMB & $0.2252 * *$ & 0.0499 & SMB & $0.2557^{*}$ & 0.0624 \\
\hline HML & -0.1011 & 0.5425 & HML & -0.1247 & 0.5599 \\
\hline WML & -0.1227 & 0.1882 & WML & $-0.1236^{*}$ & 0.0998 \\
\hline Adj. $R^{2}$ & \multicolumn{2}{|c|}{0.8457} & Adj. $R^{2}$ & \multicolumn{2}{|c|}{0.8372} \\
\hline
\end{tabular}

Notes. In this table, 'P' means portfolio and P1 shows the highest dividend-yield stock portfolio and P10 means the lowest dividend-yield stock portfolio. Alpha and EMR in this table mean the intercept of the four factor asset pricing model and excess market return, respectively. Moreover, Panel A shows the estimation results for the sample period from July 1987 to December 2008 and Panel B exhibits the results of the sample period from January 2009 to March 2013. Furthermore, ***, **,* mean the statistical significance of the coefficients at the $1 \%, 5 \%$, and $10 \%$ levels, respectively and $A d j . R^{2}$ denotes the adjusted $R$-squared value. 


\section{Macrothink}

\section{Empirical Results}

Estimation results of our four factor asset pricing model are shown in Table 2 for the dividend-yield equity portfolios in Japan, and in Table 3 for the ROE equity portfolios in Japan, respectively. More specifically, in Table 2, P1 shows the highest dividend-yield equity portfolio and P10 means the lowest dividend-yield portfolio. Further, in Table 3, P1 shows the highest ROE equity portfolio and P10 means the lowest ROE portfolio. In addition, in both Tables 2 and 3, Alpha and EMR mean the intercept of the four factor asset pricing model and excess market return, respectively. Moreover, both in Tables 2 and 3, Panel As show the results for the period from July 1987 to December 2008 and Panels B exhibit the results of the period from January 2009 to March 2013.

Documenting by focusing on the important results, first, (1) for the period from July 1987 to December 2008, there exists no positive alpha for the dividend-yield ranked portfolios; however, for the period from January 2009 to March 2013, in the second highest and third highest dividend-yield portfolios (P2 and P3 in Panel B of Table 2), we observe statistically significant positive alphas. Second, (2) for the period from July 1987 to December 2008, there exists no positive alpha for the ROE ranked portfolios; however, for the period from January 2009 to March 2013, in the second highest and third highest ROE portfolios (P2 and P3 in Panel B of Table 3), we observe statistically significant positive alphas. In sum, we understand that after the Lehman shock period, dividend yield and ROE are the fundamentals for smart portfolios in Japan.

Based on the results, we show the value evolution of the dividend-yield and ROE based portfolios and TOPIX in Figure 1. This figure is exhibited as the values equal 100 in January 2009, and the evolution in this figure is from January 2009 to March 2013. Specifically, Panel A displays the second highest dividend-yield portfolio performance; Panel B exhibits the third highest dividend-yield portfolio performance; Panel $\mathrm{C}$ shows the second highest ROE portfolio performance; and Panel D displays the third highest ROE portfolio performance. This figure shows that the second and third highest dividend-yield portfolios and the second and third highest ROE portfolios outperform the TOPIX after the Lehman shock in September 2008 . 
Table 3. Estimation results of the four factor asset pricing model for the ROE stock portfolios in Japan

\begin{tabular}{|c|c|c|c|c|c|}
\hline \multicolumn{6}{|c|}{ Panel A. Results from July 1987 to December 2008} \\
\hline \multicolumn{3}{|l|}{ P1 } & \multicolumn{3}{|l|}{$\mathrm{P} 2$} \\
\hline & Coefficient & $p$-value & & Coefficient & $p$-value \\
\hline Alpha & 0.0608 & 0.7731 & Alpha & 0.0712 & 0.6105 \\
\hline EMR & $1.0425^{* * *}$ & 0.0000 & EMR & $0.9113^{* * *}$ & 0.0000 \\
\hline SMB & -0.0561 & 0.2650 & SMB & $-0.0684 *$ & 0.0877 \\
\hline HML & $-0.1247 * * *$ & 0.0076 & HML & $-0.0910 * * *$ & 0.0084 \\
\hline WML & -0.0433 & 0.5120 & WML & $-0.1819 * * *$ & 0.0000 \\
\hline Adj. $R^{2}$ & \multicolumn{2}{|c|}{0.8026} & Adj. $R^{2}$ & \multicolumn{2}{|c|}{0.8368} \\
\hline \multicolumn{3}{|l|}{ P3 } & \multicolumn{3}{|l|}{$\mathrm{P} 4$} \\
\hline & Coefficient & $p$-value & & Coefficient & $p$-value \\
\hline Alpha & 0.1727 & 0.2089 & Alpha & 0.0757 & 0.5415 \\
\hline EMR & $0.8671 * * *$ & 0.0000 & EMR & $0.8329 * * *$ & 0.0000 \\
\hline SMB & $-0.0787^{* *}$ & 0.0489 & SMB & -0.0454 & 0.1772 \\
\hline HML & $-0.0871 * * *$ & 0.0045 & HML & -0.0079 & 0.7790 \\
\hline WML & -0.0594 & 0.1481 & WML & $-0.1039 * *$ & 0.0108 \\
\hline Adj. $R^{2}$ & \multicolumn{2}{|c|}{0.8476} & Adj. $R^{2}$ & \multicolumn{2}{|c|}{0.8451} \\
\hline \multicolumn{3}{|l|}{ P5 } & \multicolumn{3}{|l|}{ P6 } \\
\hline & Coefficient & $p$-value & & Coefficient & $p$-value \\
\hline Alpha & 0.2694 & 0.1284 & Alpha & -0.0050 & 0.9741 \\
\hline EMR & $0.8368^{* * *}$ & 0.0000 & EMR & $0.8279 * * *$ & 0.0000 \\
\hline SMB & 0.0201 & 0.7167 & SMB & 0.0546 & 0.2341 \\
\hline HML & 0.0267 & 0.5209 & HML & 0.0580 & 0.1124 \\
\hline WML & -0.1045 & 0.1658 & WML & $-0.1627 * * *$ & 0.0011 \\
\hline Adj. $R^{2}$ & \multicolumn{2}{|c|}{0.8155} & Adj. $R^{2}$ & \multicolumn{2}{|c|}{0.8145} \\
\hline \multicolumn{3}{|l|}{$\mathrm{P} 7$} & \multicolumn{3}{|l|}{ P8 } \\
\hline & Coefficient & $p$-value & & Coefficient & $p$-value \\
\hline Alpha & 0.2211 & 0.1056 & Alpha & 0.0487 & 0.7744 \\
\hline EMR & $0.9380 * * *$ & 0.0000 & EMR & $0.9226^{* * *}$ & 0.0000 \\
\hline SMB & $0.1712 * * *$ & 0.0004 & SMB & 0.0178 & 0.7535 \\
\hline HML & $0.1003^{* * *}$ & 0.0043 & HML & -0.0028 & 0.9480 \\
\hline WML & $-0.1227^{* *}$ & 0.0195 & WML & $-0.1903 * *$ & 0.0110 \\
\hline Adj. $R^{2}$ & \multicolumn{2}{|c|}{0.8566} & Adj. $R^{2}$ & \multicolumn{2}{|c|}{0.7890} \\
\hline \multicolumn{3}{|l|}{ P9 } & \multicolumn{3}{|l|}{$\mathrm{P} 10$} \\
\hline & Coefficient & $p$-value & & Coefficient & $p$-value \\
\hline Alpha & $-0.3092 *$ & 0.0758 & Alpha & -0.1586 & 0.4130 \\
\hline EMR & $1.1218^{* * *}$ & 0.0000 & EMR & $1.1509 * * *$ & 0.0000 \\
\hline SMB & $-0.1375^{* *}$ & 0.0194 & SMB & $0.2381 * * *$ & 0.0001 \\
\hline HML & $0.5014 * * *$ & 0.0000 & HML & $0.1776 * * *$ & 0.0002 \\
\hline WML & $-0.1506^{* *}$ & 0.0107 & WML & $-0.2505^{* * *}$ & 0.0001 \\
\hline Adj. $R^{2}$ & \multicolumn{2}{|c|}{0.8566} & Adj. $R^{2}$ & \multicolumn{2}{|c|}{0.8566} \\
\hline
\end{tabular}




\begin{tabular}{|c|c|c|c|c|c|}
\hline \multicolumn{3}{|l|}{$\mathrm{P} 1$} & \multicolumn{3}{|l|}{$\mathrm{P} 2$} \\
\hline & Coefficient & $p$-value & & Coefficient & $p$-value \\
\hline Alpha & 0.2813 & 0.3898 & Alpha & $0.5482 * *$ & 0.0248 \\
\hline EMR & $0.9346 * * *$ & 0.0000 & EMR & $0.8811 * * *$ & 0.0000 \\
\hline SMB & 0.1285 & 0.2962 & SMB & -0.0749 & 0.4102 \\
\hline HML & 0.0800 & 0.5622 & HML & -0.0220 & 0.8463 \\
\hline WML & -0.1560 & 0.1458 & WML & -0.0395 & 0.7085 \\
\hline Adj. $R^{2}$ & \multicolumn{2}{|c|}{0.8494} & Adj. $R^{2}$ & \multicolumn{2}{|c|}{0.8869} \\
\hline \multicolumn{3}{|l|}{ P3 } & \multicolumn{3}{|l|}{ P4 } \\
\hline & Coefficient & $p$-value & & Coefficient & $p$-value \\
\hline Alpha & $0.6663 * * *$ & 0.0013 & Alpha & 0.0435 & 0.8562 \\
\hline EMR & $0.8907 * * *$ & 0.0000 & EMR & $0.9047 * * *$ & 0.0000 \\
\hline SMB & -0.1041 & 0.1398 & SMB & $0.3134 * *$ & 0.0146 \\
\hline HML & $0.1739 * * *$ & 0.0042 & HML & 0.0637 & 0.5298 \\
\hline WML & -0.0670 & 0.2700 & WML & -0.0133 & 0.7984 \\
\hline Adj. $R^{2}$ & \multicolumn{2}{|c|}{0.9144} & Adj. $R^{2}$ & \multicolumn{2}{|c|}{0.8944} \\
\hline \multicolumn{3}{|l|}{ P5 } & \multicolumn{3}{|l|}{ P6 } \\
\hline & Coefficient & $p$-value & & Coefficient & $p$-value \\
\hline Alpha & 0.1875 & 0.4682 & Alpha & -0.1613 & 0.5266 \\
\hline EMR & $0.8359 * * *$ & 0.0000 & EMR & $0.9597 * * *$ & 0.0000 \\
\hline SMB & 0.0702 & 0.5648 & SMB & 0.1405 & 0.1819 \\
\hline HML & 0.1131 & 0.4342 & HML & $0.2833 * * *$ & 0.0011 \\
\hline WML & -0.0604 & 0.1647 & WML & $-0.1714^{* * *}$ & 0.0002 \\
\hline Adj. $R^{2}$ & \multicolumn{2}{|c|}{0.8489} & Adj. $R^{2}$ & \multicolumn{2}{|c|}{0.9102} \\
\hline \multicolumn{3}{|l|}{$\mathrm{P} 7$} & \multicolumn{3}{|l|}{ P8 } \\
\hline & Coefficient & $p$-value & & Coefficient & $p$-value \\
\hline Alpha & -0.0504 & 0.8503 & Alpha & -0.2941 & 0.4123 \\
\hline EMR & $0.9488 * * *$ & 0.0000 & EMR & $0.9839 * * *$ & 0.0000 \\
\hline SMB & 0.0985 & 0.3603 & SMB & 0.0263 & 0.7627 \\
\hline HML & 0.1798 & 0.1824 & HML & -0.1443 & 0.4417 \\
\hline WML & 0.0603 & 0.4998 & WML & -0.0221 & 0.8222 \\
\hline Adj. $R^{2}$ & \multicolumn{2}{|c|}{0.8899} & Adj. $R^{2}$ & \multicolumn{2}{|c|}{0.8277} \\
\hline \multicolumn{3}{|l|}{ P9 } & \multicolumn{3}{|l|}{$\mathrm{P} 10$} \\
\hline & Coefficient & $p$-value & & Coefficient & $p$-value \\
\hline Alpha & -0.1039 & 0.7706 & Alpha & -0.4913 & 0.3070 \\
\hline EMR & $0.9855 * * *$ & 0.0000 & EMR & $1.1753 * * *$ & 0.0000 \\
\hline SMB & 0.0813 & 0.4121 & SMB & 0.0456 & 0.8250 \\
\hline HML & 0.0613 & 0.6999 & HML & -0.1271 & 0.6208 \\
\hline WML & -0.0946 & 0.2711 & WML & $-0.2914^{* *}$ & 0.0252 \\
\hline Adj. $R^{2}$ & \multicolumn{2}{|c|}{0.8212} & Adj. $R^{2}$ & \multicolumn{2}{|c|}{0.8107} \\
\hline
\end{tabular}

Notes. In this table, 'P' means portfolio and P1 indicates the highest return on equity (ROE) stock portfolio and P10 means the lowest ROE stock portfolio. Alpha and EMR in this table mean the intercept of the four factor asset pricing model and excess market return, respectively. Moreover, Panel A presents the estimation results for the sample period from July 1987 to December 2008 and Panel B exhibits the results of the sample period from January 2009 to March 2013. Furthermore, ***,**** mean the statistical significance of the coefficients at the $1 \%, 5 \%$, and $10 \%$ levels, respectively and $A d j . R^{2}$ denotes the adjusted $R$-squared value. 


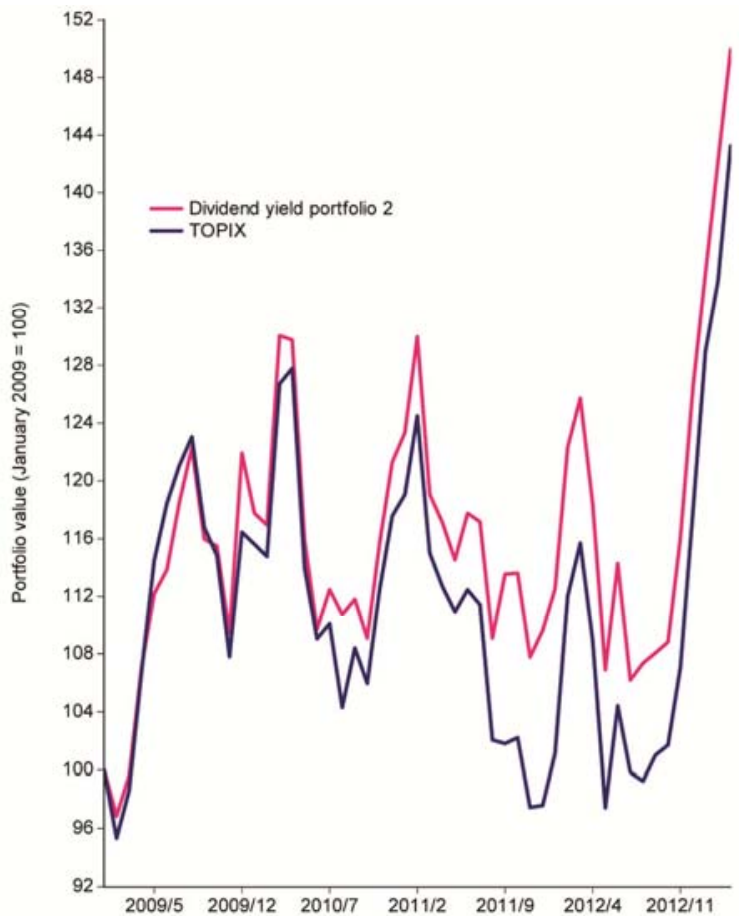

Panel A. Second highest dividend-yield portfolio

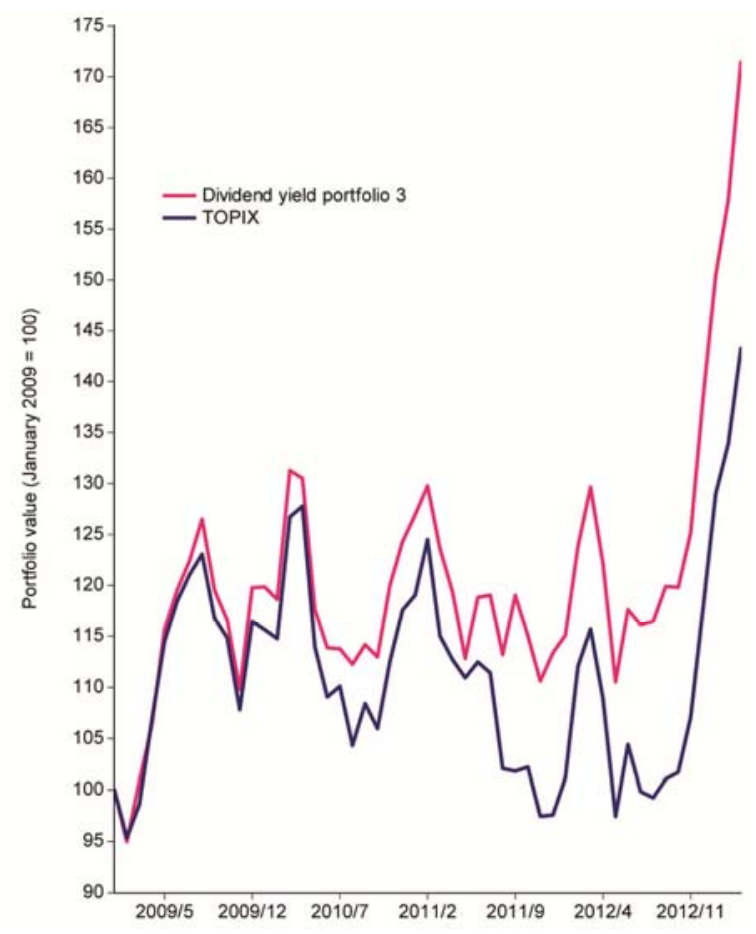

Panel B. Third highest dividend-yield portfolio

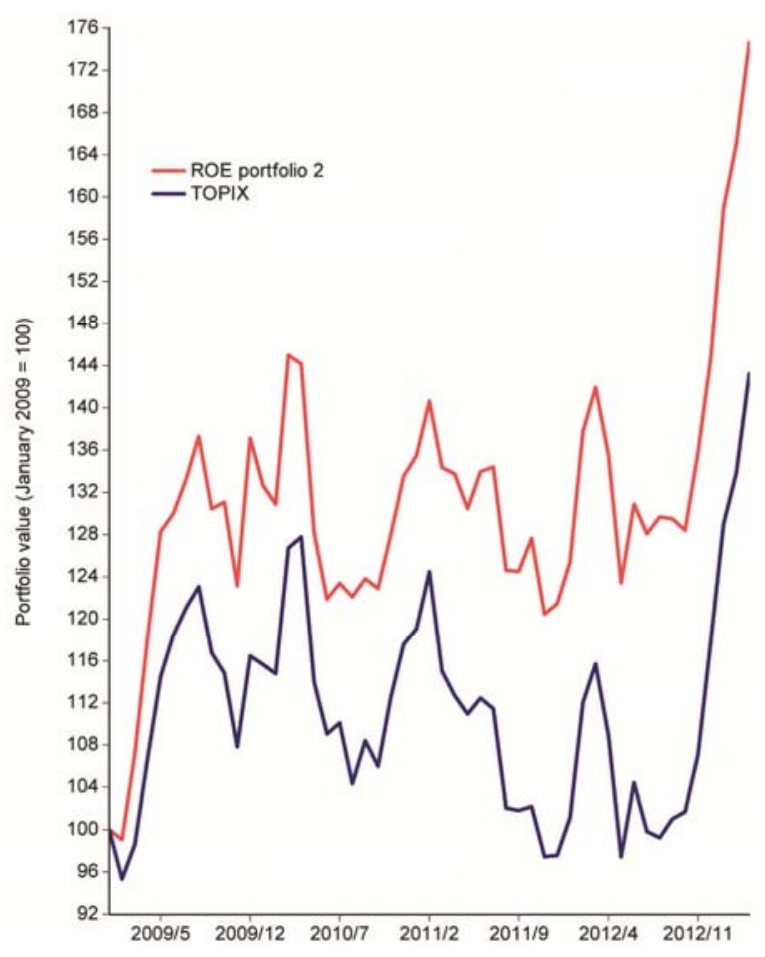

Panel C. Second highest ROE portfolio

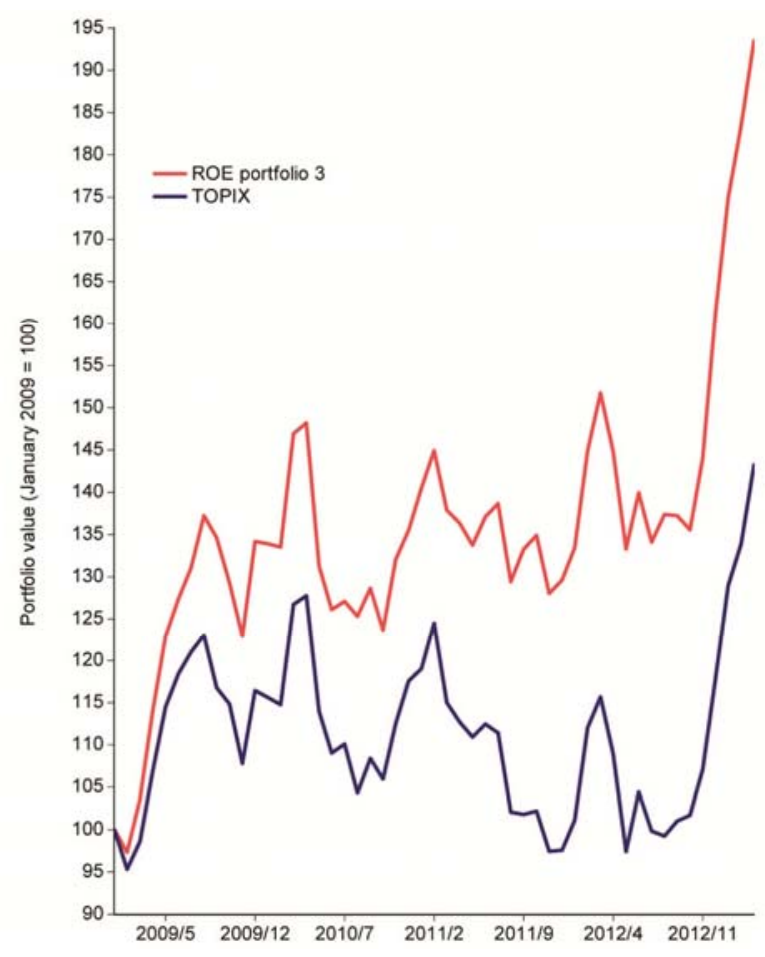

Panel D. Third highest ROE portfolio

Figure 1. Performances of the Dividend-yield and ROE Based Portfolios and TOPIX:

Evolution from January 2009 to March 2013. 


\section{Conclusions}

This paper attempted to test whether dividend yield and ROE are important fundamentals for obtaining positive alpha. As a result, our investigations derived several interesting findings as follows. First, we found that (1) for the period from January 2009 to March 2013, our second highest and third highest dividend-yield portfolios delivered statistically significant positive alphas. Second, we also found that (2) for the period from January 2009 to March 2013, our second highest and third highest ROE portfolios produced statistically significant positive alphas. To sum up, our empirical examinations demonstrated that after the Lehman shock period, dividend yield and ROE were the fundamentals for building smart portfolios in Japan.

The findings from our study shall be important for considering the effectiveness for the so-called smart beta strategies. Experiencing crucial financial crises, better risk-return profile than those from traditional market capitalization-based indices is more strongly needed in equity investments. Continuing this line of empirical research is one of our future tasks.

\section{Acknowledgement}

I am particularly grateful to the repeated kind invitation from the journal to write to this journal. I also appreciate the Chuo University Grant for Special Research for the generous financial assistance to this research. Moreover, I thank the anonymous referees for their kind comments on this paper. I also thank Stefano Marmi for providing data for this research.

Furthermore, I particularly thank the Editor, Cathy Green, for the kind invitation to this journal. Finally, I deeply thank all the Editors of this journal for their kindness to this paper.

\section{References}

AlMahdi, S. (2015). Smart beta portfolio optimization. Journal of Mathematical Finance, 5, 202-211. http://dx.doi.org/10.4236/jmf.2015.52019

Bertrand, P., \& Lapointe, V. (2015). How performance of risk-based strategies is modified by socially responsible investment universe? International Review of Financial Analysis, 38, 175-190. http://dx.doi.org/10.1016/j.irfa.2014.11.009

Fama, E. F., \& French, K. R. (1993). Common risk factors in the returns on stocks and bonds. Journal of Financial Economics, 33, 3-56. http://dx.doi.org/10.1016/0304-405X(93)90023-5

Hsu, J., Kalesnik, V., \& Viswanathan, V. (2015). A framework for assessing factors and implementing smart beta strategies. Journal of Index Investing, 6, 89-97. http://dx.doi.org/10.3905/jii.2015.6.1.089

Malkiel, B. G. (2014). Is smart beta really smart? Journal of Portfolio Management, 40, 127-134. http://dx.doi.org/10.3905/jpm.2014.40.5.127

Shepherd, S. (2014). Smart beta investing in corporate bonds: Conceptual and empirical grounds. White Paper, Research Affiliates. 


\section{Copyright Disclaimer}

2016, Vol. 4, No. 1

Copyright for this article is retained by the author(s), with first publication rights granted to the journal.

This is an open-access article distributed under the terms and conditions of the Creative Commons Attribution license (http://creativecommons.org/licenses/by/3.0/). 